\title{
Efficacy of piroxicam for postoperative pain after lower third molar surgery associated with CYP2C8*3 and CYP2C9
}

This article was published in the following Dove Press journal: Journal of Pain Research 6 July 2017

Number of times this article has been viewed

\author{
Adriana Maria Calvo \\ Paulo Zupelari-Gonçalves \\ Thiago José Dionísio \\ Daniel Thomas Brozoski \\ Flávio Augusto Faria \\ Carlos Ferreira Santos
}

Department of Biological Sciences, Bauru School of Dentistry, University of São Paulo, São Paulo, Brazil
Objective: Nonsteroidal anti-inflammatory drugs (NSAIDs) are metabolized by the cytochrome P450 enzymes (CYPs), predominantly CYP2C8 and CYP2C9. The aim of this study was to evaluate the possible association of polymorphisms in the $C Y P 2 C 8 * 3$ and $C Y P 2 C 9$ genes with the clinical efficacy of oral piroxicam ( $20 \mathrm{mg}$ daily for 4 days) after lower third molar surgeries with regard to postoperative pain, swelling, trismus, adverse reactions, need for rescue medication and the volunteer's overall satisfaction.

Materials and methods: For this purpose, 102 volunteers were genotyped for $C Y P 2 C 8 * 3$ and $C Y P 2 C 9$ polymorphisms. Briefly, genomic DNA was isolated from saliva collected from volunteers subjected to invasive lower third molar surgeries, and the preoperative, intraoperative and postoperative parameters were collected and analyzed.

Results: An equal amount of piroxicam sufficiently managed postoperative pain and inflammatory symptoms, with visual analog pain scores typically $<40 \mathrm{~mm}$ for all genotypes investigated. Furthermore, only two out of 102 volunteers heterozygous for $C Y P 2 C 8^{*} 3$ and $C Y P 2 C 9^{*} 3$ reported adverse side effects.

Conclusion: In general, slow metabolizers of piroxicam, who were volunteers with mutant alleles, were indifferent from normal metabolizers with the wild-type alleles and therefore did not require specialized piroxicam doses to manage postoperative pain and inflammation.

Keywords: piroxicam, lower third molar surgery, P450, CYP2C8, CYP2C9, pharmacogenetics

\section{Introduction}

The variability in each individual's response to the same dose of a drug is a major cause of side effects. In many cases, this variability is connected to polymorphisms in genes encoding enzymes responsible for metabolizing drugs. ${ }^{1}$ In particular, carriers of mutations in genes encoding drug-metabolizing enzymes tend to have higher plasma levels of the drug ${ }^{2,3}$ and an increase in the frequencies and severity of adverse reactions, when compared to nonmutants, when taking the usual doses of a drug that is metabolized by the affected enzyme. ${ }^{4-6}$ In other words, these mutations, which may consist of an alteration in one nucleotide, can cause absent, reduced or increased enzymatic activity. ${ }^{2,7}$ In particular, cytochrome P450 2C8 (CYP2C8) and 2C9 (CYP2C9) belong to one of the major families of enzymes involved in drug metabolism.

The genes encoding CYP2C8 and CYP2C9 are grouped in two consecutive clusters on chromosome $10 .{ }^{3}$ Briefly, a single-nucleotide polymorphism (SNP) is a variant DNA sequence wherein one nucleotide differs between common populations in a species. ${ }^{8}$ Furthermore, these SNPs are commonly found in exons and introns. The common nomenclature for the normal wild-type (wt) SNP for CYP2C9 is noted with
Correspondence: Carlos Ferreira Santos Department of Biological Sciences, Bauru School of Dentistry, University of São Paulo, Alameda Doutor Octávio Pinheiro Brisolla, 9-75, Bauru, São Paulo I70|2-90|, Brazil

Tel +55 I4 32358295

Email cfsantos@fob.usp.br 
a *1; two common polymorphic variants are allele $* 2$, with the amino acid change $\mathrm{R} 144 \mathrm{C}$, and allele $* 3$ with the amino acid change I359L; each individual commonly carries two alleles and may be either homozygous or heterozygous, in both cases, mutant (mt). ${ }^{9}$

Both CYP2C8 and CYP2C9 enzymes are associated with the metabolism of several drugs used clinically, some of which possess narrow therapeutic margins. ${ }^{10}$ The clinical importance of $C Y P 2 C 8$ and $C Y P 2 C 9$ polymorphisms with regard to nonsteroidal anti-inflammatory drugs (NSAIDs) mainly involves two factors: 1) these polymorphisms are often associated with an increased number of adverse reactions; and 2) these adverse reactions are often more serious. Notably, "slow" metabolizers of piroxicam (eg, people with CYP $2 C 9 * 1 / * 3$ and $* 3 / * 3$ alleles), when compared to normal metabolizers (eg, people with $C Y P 2 C 9 * 1 / * 1$ wt alleles), might respond differently to the same dose of piroxicam, although it remains unknown whether piroxicam is metabolized differently by either CYP variant depending on whether these molecules are in ketonic or enolic tautomeric forms.

Data regarding the main role of CYP2C8 in the metabolism of piroxicam are inconsistent, but some studies suggest that SNPs of $C Y P 2 C 8$ tend to decrease the clearance of NSAIDs in general. ${ }^{9}$ Several studies have associated the genotypes of $C Y P 2 C 8$ and $C Y P 2 C 9$ with the pharmacokinetics and pharmacodynamics of piroxicam and other NSAIDs in healthy individuals. ${ }^{4,11-15}$ In contrast, this study aimed to evaluate the possible association of polymorphisms of $C Y P 2 C 8^{*} 3, C Y P 2 C 9^{*} 2$ and $C Y P 2 C 9 * 3$ with the clinical efficacy of oral piroxicam (20 mg daily for 4 days) after invasive lower third molar surgeries with regard to pain, swelling, trismus, need for rescue medication, volunteer satisfaction and adverse reactions to piroxicam. Briefly, the volunteers selected for this study required invasive surgeries for lower third molars with the following classifications: Pell and Gregory class IIB, IIC, IIIA, IIIB and IIIC and/or Winter horizontal, distal, inverted and transalveolar. ${ }^{16}$ It was hypothesized that postoperative pain would be effectively managed by a daily $20 \mathrm{mg}$ oral dose of piroxicam for all genotypes, but that volunteers with mutant $C Y P 2 C 8 * 3$ and $C Y P 2 C 9$ genotypes would report less postoperative pain after lower third molar surgery.

\section{Materials and methods}

\section{Registration and study design}

The current study was performed in accordance with the Declaration of Helsinki and was approved by the ethics committee of Bauru School of Dentistry, University of São
Paulo, Brazil National Research Ethics System (CAAE number: 20657913.7.0000.5417) in accordance with resolution 196/96 of the National Council of Health/Ministry of Health. This study was registered with Universal Trial (U1111-1155-3545); ClinicalTrials.gov (NCT02450487). All volunteers provided signed informed consent agreements after receiving all instructions and before undergoing any interventions.

Briefly, 105 volunteers ( $\geq 18$ years old) visiting the Clinical Physiology and Pharmacology Laboratory (LAFFIC) requiring the extraction of at least one lower third molar that was included and/or impacted (as determined by panoramic radiography) participated in this study. Three volunteers did not return for postoperative measurements and were completely excluded from this study (Figure 1). Saliva samples were collected to genotype all volunteers, and postoperative data were used to judge the clinical efficacy of piroxicam (20 mg daily for 4 days) after lower third molar surgeries.

Eligibility criteria included adults without inflammation, infection and systemic diseases that could possibly interfere with the study. Exclusion criteria were as follows: any history of allergy, gastrointestinal bleeding/ulcers, kidney disease, asthma or any known allergic sensitivity to any NSAID. Pregnant women were also excluded from the study, as well as volunteers who used antidepressants, diuretics or NSAIDs 7 days prior to the start of the experiments. All surgeries were performed between December 2013 and October 2014, after ethical approval. The sample size calculation for the current study was based on the facial edema and trismus parameters from our previous research article. ${ }^{17}$ Taking into account the facial edema data with $94 \%$ power and effect size of 0.7 , the number of patients required was 102 ; considering trismus with $80 \%$ power and effect size of 0.56 , the number of patients remained 102 .

All surgeries required bone removal, and, in some cases, tooth section. The positions of molars were determined with panoramic radiographs. No antibiotics were prescribed during the study to avoid possible bias in the drug protocol. ${ }^{17}$

\section{Surgery intervention and assessments}

All surgeries were performed by the same maxillofacial surgeon (PZG). One cartridge $(1.8 \mathrm{~mL})$ of local anesthetic (4\% articaine with 1:200,000 epinephrine) was injected near the buccal, lingual and inferior alveolar nerves to achieve truncal anesthesia. After 3 minutes and when the patient confirmed a loss of sensation of the lower lip, a half cartridge $(0.9 \mathrm{~mL})$ of local anesthetic was injected to obtain complete and consistent anesthesia. A half cartridge $(0.9 \mathrm{~mL})$ 


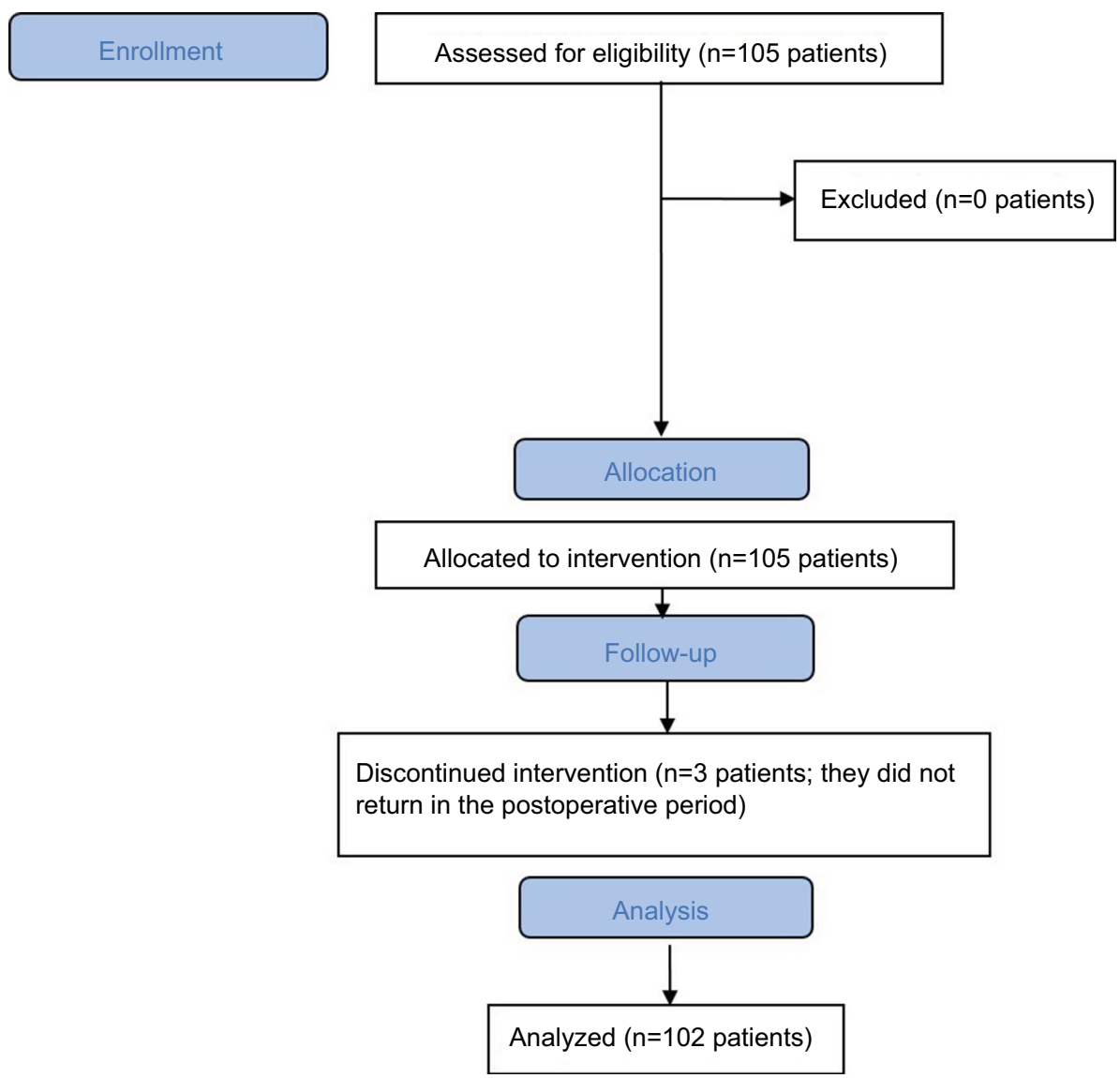

Figure I CONSORT flowchart.

of local anesthetic was also administered using the terminal infiltration technique to reduce bleeding and ensure mucosal anesthesia. $^{16-24}$

The protocol used for postoperative pain medication after extraction of the third lower molars was a self-administered $20 \mathrm{mg}$ tablet of piroxicam once every 24 hours for 4 days. Oral rescue analgesic medication was also available as needed throughout the study; for that, $750 \mathrm{mg}$ tablets of paracetamol were provided to all volunteers, who were instructed to record the time of consumption while maintaining the use of piroxicam. ${ }^{16-19,21-26}$

The preoperative, intraoperative and postoperative parameters evaluated are reported in Table 1. Briefly, postoperative mouth opening (millimeters) between the mesial-incisal corners of the upper and lower right central incisors during maximum opening of the jaws was measured and recorded before surgery as well as during the second and seventh postoperative days, according to Ustun et al. ${ }^{16,24,27}$

For swelling measurements of the facial edema, methods were used according to Ustun et al, which sums the following measures: 1) the distance between the lateral canthal ligament and the gonion; 2) the distance between the tragus and the labial commissure of the mouth; and 3) the distance between the tragus and the soft tissue of pogonion. ${ }^{16,24,27}$ The preoperative sum of these three measures was considered the baseline. The percentage difference between the baseline value and the values of the second and seventh postoperative periods for swelling indicated the facial edema.

\section{Genotyping CYP2C8*3 and CYP2C9}

All volunteers were instructed to expectorate up to $4 \mathrm{~mL}$ of unstimulated saliva into a provided sterile polypropylene collection tube. Approximately $3 \mathrm{~mL}$ of the tube's contents were then placed in a sterile microcentrifuge tube using a sterile pipette and immediately stored in a freezer at $-20^{\circ} \mathrm{C}$ until the genomic DNA was extracted. Finally, a QIAamp DNA Mini Kit (catalog number 51104; Qiagen ${ }^{\circledR}$, Hilden, Germany) was used to extract genomic DNA from the saliva.

Genomic DNA was genotyped using the Taqman ${ }^{\circledR}$ system for performing real-time polymerase chain reaction (qPCR) using a ViiA ${ }^{\mathrm{TM}} 7$ system (Applied Biosystems ${ }^{\circledR}$, Waltham, MA, USA). Each reaction was performed in duplicate. Specifically, manufactured assays were used and validated by Applied Biosystems ${ }^{\circledR}$ with the following catalog numbers: 
Table I Study parameters evaluated

\begin{tabular}{|c|c|}
\hline Parameters & Units \\
\hline Total volume of local anesthetic & Milliliters \\
\hline Onset of anesthetic agent action & Minutes \\
\hline Surgery duration & Minutes \\
\hline $\begin{array}{l}\text { Overall experience of surgery reported by } \\
\text { volunteer }\end{array}$ & 5-point scale: I, poor; 2 , fair; 3 , good; 4 , very good; 5 , excellent \\
\hline Quality of anesthesia & $\begin{array}{l}\text { 3-point scale: I, no discomfort during surgery; } 2 \text {, any discomfort without anesthesia required; } 3 \text {, } \\
\text { any discomfort with anesthesia required }\end{array}$ \\
\hline Surgery difficulty & $\begin{array}{l}\text { 3-point scale: I, no need for osteotomies without tooth sectioning; } 2 \text {, need for osteotomies } \\
\text { without tooth sectioning; } 3 \text {, need for osteotomies as well as tooth sectioning complicated }\end{array}$ \\
\hline Intraoperative bleeding & 3-point scale: I, minimal bleeding; 2 , normal bleeding; 3 , excessive bleeding \\
\hline Quality of wound healing & $\begin{array}{l}\text { 7th day, 3-point scale: I, normal healing without inflammation; } 2 \text {, delayed healing; } 3 \text {, healing } \\
\text { complicated by inflammation or local infection with or without purulent material }\end{array}$ \\
\hline Adverse reactions & $\begin{array}{l}\text { Observed by the surgeon or reported by the volunteer, during the surgery in the first } \\
\text { postoperative hour and during the } 2 \text { nd and } 7 \text { th days after surgery }\end{array}$ \\
\hline $\begin{array}{l}\text { Systolic, diastolic and mean arterial pressure; } \\
\text { heart rate; and oxygen saturation }{ }^{\mathrm{a}}\end{array}$ & $\begin{array}{l}\text { Millimeters of mercury }(\mathrm{mmHg}) \text {; beats per minute }(\mathrm{bpm}) \text {; and percentage saturation of peripheral } \\
\text { oxygen }\left(\% \mathrm{SpO}_{2}\right)\end{array}$ \\
\hline Body temperature & Preoperative period, 2 nd, 7 th postoperative day (degrees centigrade, ${ }^{\circ} \mathrm{C}$ ) \\
\hline Mouth opening & Preoperative period, 2nd, 7th postoperative day (millimeters) \\
\hline Facial swelling & Preoperative period, 2nd, 7th postoperative day (millimeters) \\
\hline Subjective evaluation of postoperative pain & VAS $(0-100 \mathrm{~mm})$ \\
\hline Total amount of rescue medication & Number of tablets \\
\hline
\end{tabular}

Note: ${ }^{a}$ Dixta ${ }^{\circledR}$ (model DX202I; Dixtal Biomédica Industria and Comércio Ltda, Marília, São Paulo, Brazil; ANVISA/MS I0293490035, model number I0I503732).

Abbreviation: VAS, visual analog scale.

C_25628505_10, C_27104892_10, C_25625794_10 and C_256257782_20; CYP2C9 [CYP2C9*2-rs1799853 $(\mathrm{C} 430 \rightarrow \mathrm{T})$ and $C Y P 2 C 9 * 3-\mathrm{rs} 1057910(\mathrm{~A} 1075 \rightarrow \mathrm{C})]$ and $C Y P 2 C 8[C Y P 2 C 8 * 3$-rs $11572080(\mathrm{G} 416 \rightarrow \mathrm{A})$ and rs10509681 (A1196 $\rightarrow$ G), respectively]. DNA samples were quantified and qualified using TaqMan ${ }^{\circledR}$ Genotyping Master Mix (catalog number: 4381656; Applied Biosystems ${ }^{\circledR}$ ) to determine the $C Y P$ genotypes.

\section{Statistical analysis}

The G*Power software v.3.0.10 was used for the sample calculation. Data were analyzed using Microsoft ${ }^{\circledR}$ Excel 2002 (version 10.6871.6870) and GraphPad Prism (version 4.0). Briefly, data were tested for normality using the Shapiro-Wilk test. When data were normally distributed, comparisons among and between groups were made using the unpaired $t$-test. For all nonnormally distributed data, statistical comparisons between two independent groups were performed using the Mann-Whitney $U$ test, while the Kruskal-Wallis test by ranks was used for analyzing nonparametric data with more than two groups. Lastly, binary data (eg, the absence or presence of an adverse reaction) were compared using Fisher's exact test.

Statistical significance was set at 0.05 . Normally distributed data are reported as mean $\pm \mathrm{SD}$, whereas nonnormally distributed data are reported as median with the interquartile range (IQR).

\section{Results}

Table 2 reports the demographic distribution and intraoperative parameters of the 102 volunteers with lower third molar surgeries. Human subjects were between the ages of 14 and 58 years and came from the state of São Paulo, Brazil.

Excluding the transalveolar position, the third molar position of the tooth to be extracted was evenly distributed $(P=0.61)$. The transalveolar-positioned third molars overall were significantly less common $(2.9 \%)$ than other molar positions (mesioangular, vertical, distoangular or horizontal) when compared to positions being equally distributed (chisquare test, $P=0.00036$ ).

Hemodynamic parameters obtained during surgery fluctuated slightly during the different phases of extraction, yet no unusual peaks in blood pressure, heart rate and oxygen saturation were observed (data not shown). Additionally, during and immediately following surgery, no adverse reactions were found in any of the volunteers. Throughout the entire study, only two volunteers reported adverse side effects; on the second day, one volunteer reported sleepiness $\left(C Y P 2 C 8^{*} 3 \mathrm{mt}\right.$ and $C Y P 2 C 9 * 1 / * 3$ genotype $)$ and one volunteer $(C Y P 2 C 8 * 3$ mt and $C Y P 2 C 9 * 1 / * 3$ genotype) reported stomachaches. In addition, as indicated by some of the postoperative parameters, a volunteer's allele for $C Y P 2 C 8 * 3$ or $C Y P 2 C 9$ was not correlated with any variation in the anti-inflammatory effects of piroxicam. 
Table 2 Preoperative, intraoperative and postoperative parameters

\begin{tabular}{|c|c|c|}
\hline \multirow{2}{*}{$\begin{array}{l}\text { Parameters } \\
\text { Age, years }\end{array}$} & \multicolumn{2}{|c|}{ All $(n=102)$} \\
\hline & Median & IQR \\
\hline & 24 & 7 \\
\hline Lower third molar position & $\mathbf{n}$ & $\%$ \\
\hline Distoangular & 27 & 26 \\
\hline Horizontal & 27 & 26 \\
\hline Mesioangular & 19 & 19 \\
\hline Transalveolar & I & 1 \\
\hline Vertical & 28 & 27 \\
\hline Surgery & Median & IQR \\
\hline Duration, minutes & 10 & 7 \\
\hline Difficulty (score assessed by surgeon) & 3.0 & 1.0 \\
\hline $\begin{array}{l}\text { Intraoperative bleeding (score assessed by } \\
\text { surgeon) }\end{array}$ & 1.0 & 0.1 \\
\hline $\begin{array}{l}\text { Quality of surgery (score assessed by } \\
\text { volunteer) }\end{array}$ & 3.5 & 1.0 \\
\hline $\begin{array}{l}\text { Quality of wound healing (score assessed by } \\
\text { surgeon) }\end{array}$ & 1.0 & 0.0 \\
\hline $\begin{array}{l}\text { Local anesthetic, } 4 \% \text { articaine with } \\
\text { I:200,000 epinephrine }\end{array}$ & Median & IQR \\
\hline Quantity, mL & 2.7 & 0.9 \\
\hline Onset, minutes & 1.0 & 0.5 \\
\hline Quality (score assessed by surgeon) & 1.5 & 2.0 \\
\hline Mouth opening & Average & SD \\
\hline \multirow[t]{2}{*}{ Preoperative measurement, $\mathrm{mm}$} & 47 & 7 \\
\hline & Median & IQR \\
\hline $\begin{array}{l}\text { 2-day postoperative measurement, percentage } \\
\text { of preoperative }\end{array}$ & 42 & 18 \\
\hline $\begin{array}{l}\text { 7-day postoperative measurement, percentage } \\
\text { of preoperative }\end{array}$ & 71 & 31 \\
\hline Facial swelling & Median & IQR \\
\hline Preoperative measurement, mm & 37 & 4 \\
\hline $\begin{array}{l}\text { 2-day postoperative measurement, percentage } \\
\text { of preoperative }\end{array}$ & 104 & 4 \\
\hline $\begin{array}{l}\text { 7-day postoperative measurement, percentage } \\
\text { of preoperative }\end{array}$ & 100 & 2 \\
\hline Underarm temperature, ${ }^{\circ} \mathrm{C}$ & Median & IQR \\
\hline Preoperative measurement & 36.2 & 0.7 \\
\hline 2-day postoperative measurement & 36.3 & 0.7 \\
\hline 7-day postoperative measurement & 36.1 & 0.6 \\
\hline Paracetamol rescue medication & Median & IQR \\
\hline \multirow[t]{2}{*}{$\begin{array}{l}\text { Time between first consumption and surgery, } \\
\text { hours }\end{array}$} & 3.5 & 3.5 \\
\hline & Average & SD \\
\hline \multirow[t]{2}{*}{ VAS during first consumption, $\mathrm{mm}$} & 53 & 25 \\
\hline & Median & IQR \\
\hline Total quantity consumed, mg & 2250 & 3750 \\
\hline
\end{tabular}

Abbreviations: IQR, interquartile range; VAS, visual analog scale.
The distribution of genotypes is reported in Table 3. Overall, all the volunteers grouped together were $72.5 \%$ homozygous for the wt $C Y P 2 C 8^{*} 3$ allele and $27.5 \%$ heterozygous or homozygous for the mt $C Y P 2 C 8 * 3$ allele (Table 3 ). Furthermore, volunteers grouped together were most commonly homozygous for the wt $C Y P 2 C 9 * 1 / * 1$ allele $(66.7 \%)$, followed by the $m$ t variants $* 1 / * 2(19.6 \%), * 1 / * 3(7.8 \%)$ and $* 3 / * 3(5.9 \%)$, with no $* 2 / * 2$ or $* 2 / * 3$ genotypes found in the study population (Table 3 ). Table 4 reports the frequencies of the $C Y P 2 C 8 * 3$ alleles compared to the $C Y P 2 C 9$ alleles found in the population of volunteers.

Piroxicam was effective in the control of pain regardless of the $C Y P$ haplotype $(C Y P 2 C 8 * 3$ and $C Y P 2 C 9$ ) carried by volunteers (Figure 2). There was a trend of lower levels of reporting pain (visual analog scale [VAS]) in volunteers carrying the $C Y P 2 C 9^{*} 1 /{ }^{*} 1 \mathrm{wt}$ allele, though a statistically significant difference was not found between groups. This trend is justified considering reports in the literature that ancient homozygous individuals for $C Y P 2 C 9$ are normal metabolizers of piroxicam.

It is noted that the average pain scores reported by the volunteers is $<44 \mathrm{~mm}$, which demonstrates a very high pain control profile for piroxicam independent of the $C Y P$ haplotype carried by the volunteers.

\section{Discussion}

This is the first report focusing on the influence of pharmacogenetics of the P450 cytochrome family (CYP2C $8 * 3$ and $C Y P 2 C 9$ ) on the control of postoperative inflammatory signs after minor oral surgery. The vast majority of articles are related to pharmacokinetics, metabolism and adverse reactions of NSAIDs, such as gastrointestinal bleeding, ${ }^{2-6,10,12,13,28}$

Table 3 Genotype frequencies of CYP2C8*3 and CYP2C9

\begin{tabular}{lll}
\hline Allele & All $(\mathbf{n}=\mid \mathbf{2 0})$ & \\
\cline { 2 - 3 } & $\mathbf{n}$ & $\%$ \\
\hline CYP2C8*3 & 74 & 72.5 \\
Wild type (wt) & 28 & 27.5 \\
Mutant (mt) & & \\
CYP2C9 & 68 & 66.7 \\
$* 1 / * 1$ & 20 & 19.6 \\
$* 1 / * 2$ & 0 & 0.0 \\
$* 2 / * 2$ & 0 & 0.0 \\
$* 2 / * 3$ & 8 & 7.8 \\
$* 1 / * 3$ & 6 & 5.9 \\
$* 3 / * 3$ & & \\
\hline
\end{tabular}

Abbreviation: CYP, cytochrome P450. 
Table 4 Genotypic frequencies of CYP2C8 relative to CYP2C9 in a Brazilian population of volunteers with third molar surgeries

\begin{tabular}{|c|c|c|c|c|c|c|c|c|}
\hline \multirow{3}{*}{$\begin{array}{l}\text { Genotypes } \\
\text { CYP2C9 }\end{array}$} & \multicolumn{8}{|l|}{ CYP2C8*3 } \\
\hline & \multicolumn{2}{|l|}{$* I / * I$} & \multicolumn{2}{|l|}{$* 1 / * 3$} & \multicolumn{2}{|l|}{$* 3 / * 3$} & \multicolumn{2}{|l|}{ All } \\
\hline & rsl050968I & rsII572080 & rs 10509681 & rs I I572080 & rsl050968I & rs $1 / 572080$ & rs 10509681 & rsII572080 \\
\hline$* 1 / * 1$ & $63(61.8 \%)$ & $63(61.8 \%)$ & 5 (4.9\%) & 5 (4.9\%) & $0(0.0 \%)$ & $0(0.0 \%)$ & 68 (66.7\%) & 68 (66.7\%) \\
\hline$* 1 / * 2$ & $2(2.0 \%)$ & 4 (3.9\%) & 17 (16.7)\% & $16(15.7 \%)$ & I (I.0\%) & $0(0.0 \%)$ & 20 (19.6\%) & 20 (19.6\%) \\
\hline$* 2 / * 2$ & $0(0.0 \%)$ & $0(0.0 \%)$ & $0(0.0 \%)$ & $0(0.0 \%)$ & $0(0.0 \%)$ & $0(0.0 \%)$ & $0(0.0 \%)$ & $0(0.0 \%)$ \\
\hline$* 2 / * 3$ & $0(0.0 \%)$ & $0(0.0 \%)$ & $0(0.0 \%)$ & $0(0.0 \%)$ & $0(0.0 \%)$ & $0(0.0 \%)$ & $0(0.0 \%)$ & $0(0.0 \%)$ \\
\hline$* 1 / * 3$ & $6(5.9 \%)$ & 7 (6.9\%) & $2(2.0 \%)$ & I (I.0\%) & $0(0.0 \%)$ & $0(0.0 \%)$ & $8(7.8 \%)$ & $8(7.8 \%)$ \\
\hline$* 3 / * 3$ & $4(3.9 \%)$ & $4(3.9 \%)$ & $2(2.0 \%)$ & $2(2.0 \%)$ & $0(0.0 \%)$ & $0(0.0 \%)$ & $6(5.9 \%)$ & $6(5.9 \%)$ \\
\hline All & 75 (73.5\%) & & $26(25.5 \%)$ & & I (I.0\%) & & $102(100 \%)$ & \\
\hline
\end{tabular}

Abbreviation: CYP, cytochrome P450.
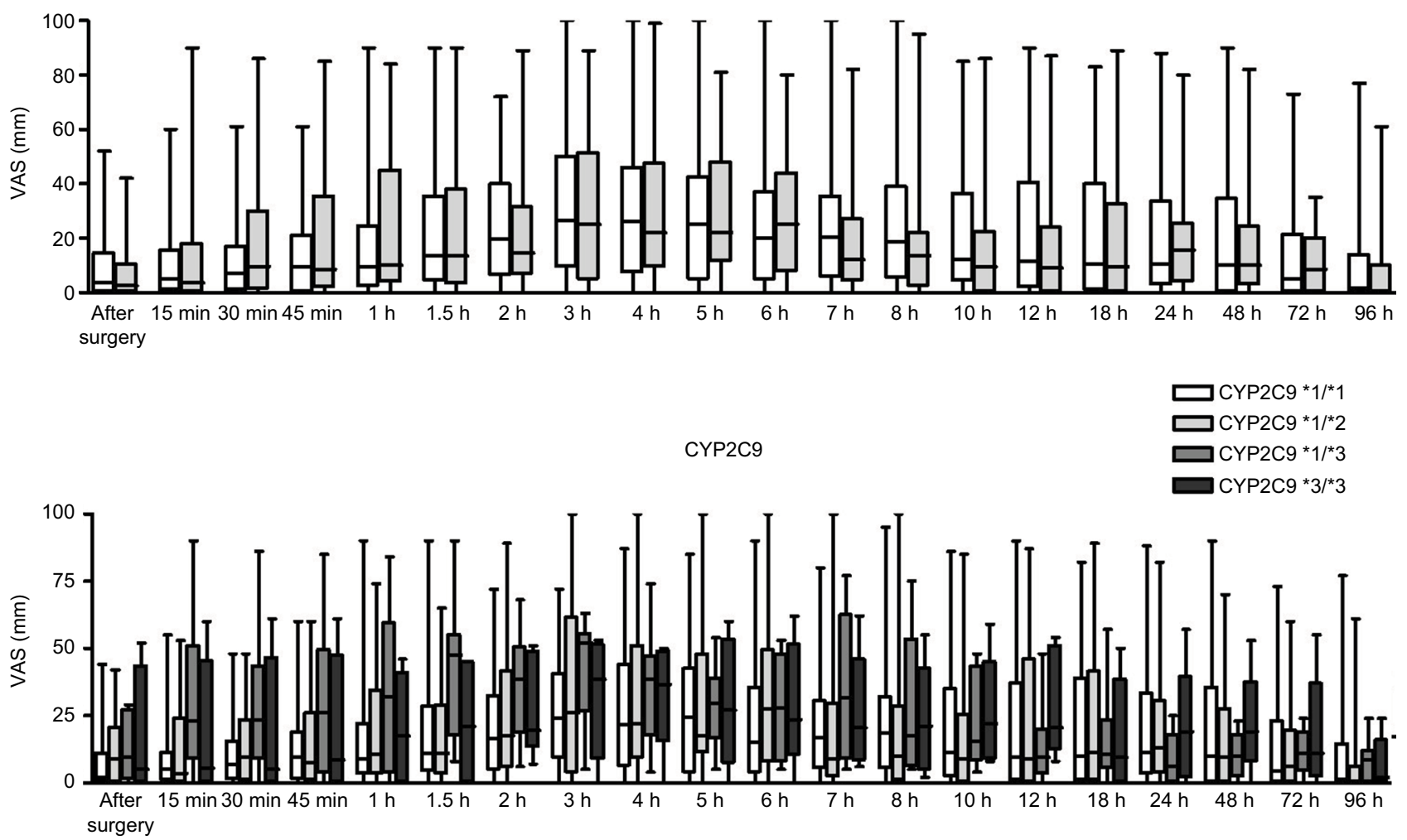

Figure 2 Postoperative pain scores reported by volunteers.

Notes: VAS of self-reported postoperative pain scores after lower third molar surgeries assessed at $0.25,0.5,0.75,1,1.5,2,3,4,5,6,7,8,10,12,18,24,48,72$ and 96 hours. Scores could range from 0 to $100 \mathrm{~mm}$, with larger scores indicating increased pain. The top frame refers to the CYP2C8*3-and the lower frame to CYP2C9-bearing volunteers. Abbreviations: CYP, cytochrome P450; VAS, visual analog scale; mt, mutant; wt, Wild type.

but not the clinical control of inflammatory signs after surgical procedures. Some articles have shown pharmacogenetic impacts on large surgeries, such as the need for prior genetic analysis of patients before bariatric surgeries, regarding the lower use of opioids and lower rates of postoperative pain; ${ }^{29}$ The study of Murto et al ${ }^{30}$ shows the impact of $C Y P 2 C 9^{*} 3$ on lower postoperative pain rates after adenotonsillectomy surgeries in children taking celecoxib.
It was speculated that postoperative pain would be effectively managed by piroxicam ( $20 \mathrm{mg}$ daily for 4 days) for all genotypes, but that all volunteers with $C Y P 2 C 8 * 3$ $\mathrm{mt}$ and $C Y P 2 C 9$ genotypes might have experienced less postoperative pain. It was also possible that adverse side effects would be decreased in volunteers with the wt alleles when compared to volunteers with the mutant alleles. In other words, individuals with mutant alleles for $C Y 2 C 8 * 3$ 
and $C Y P 2 C 9$ might have less pain or more side effects when compared to individuals with wt alleles for $C Y 2 C 8 * 3$ and CYP2C9. However, postoperative pain scores among the volunteers were not different when comparing the groups of both $C Y P 2 C 8 * 3$ and $C Y P 2 C 9$.

Jensen et $\mathrm{al}^{31}$ noted that patients undergoing postoperative pain reporting $<44 \mathrm{~mm}$ (VAS) tend to describe their pain as mild or having minimal impact on their daily activities. In this study, volunteers reported pain scores on average $<40 \mathrm{~mm}$. Similarly, Rollason et $\mathrm{al}^{1}$ reported that the average postoperative pain score reported by their volunteers was $<44 \mathrm{~mm}$, demonstrating effective postoperative pain management that was independent of their $C Y P$ genotype. These data are clinically important since, for this type of surgery, with signs of acute pain and punctal inflammation that tend to cease within 2-3 days, patients presenting the ancestral version of $C Y P 2 C 8 * 3$ and $C Y P 2 C 9$ do not require piroxicam dose adjustment.

The main importance of pharmacogenetic clinical studies after the consumption of NSAIDs is the occurrence of gene-related changes in pharmacokinetics producing side effects rather than a change in the efficacy profile. In general, carriers of mutations in genes encoding drug-metabolizing enzymes, when treated with the usual doses of a drug metabolized by the affected enzyme, tend to have increased plasma levels of the drug, faster rate of absorption relative to its elimination and increased frequency and severity of adverse reactions with the use of these drugs. ${ }^{4-7,13}$ Adverse side effects noted by the surgeon or the volunteers were rare in this study, with only two individuals reporting mild adverse reactions related to consuming their daily $20 \mathrm{mg}$ dose of piroxicam. Thus, no correlations were found between genotype and adverse side effects in this regimen of prescription for the control of inflammatory signs after surgeries of lower third molars with piroxicam.

Other studies with large samples report increased risks of gastrointestinal bleeding when patients consuming NSAIDs carried the $C Y P 2 C 9 * 2$ and $C Y P 2 C 9 * 3$ mutant alleles, ${ }^{1,5,32}$ although they state that this risk of gastrointestinal bleeding is clearly dose related and the pharmacokinetics shows greater exposure to these drugs in carriers of the $C Y P 2 C 9 * 2$ and *3 alleles. Recommendations for dose adjustments in those patients are currently only for celecoxib and flurbiprofen. ${ }^{1}$ Martinez et al genotyped $C Y P 2 C 9$ in subjects who consumed various NSAIDs that are metabolized by CYP2C9 (ibuprofen, indomethacin, celecoxib, valdecoxib, lornoxicam, tenoxicam, meloxicam and piroxicam) and other NSAIDs not considered CYP2C9 substrates (salicylate and acetaminophen). ${ }^{5}$ These authors concluded that the association of the variant $C Y P 2 C 9$ alleles with the risk of gastrointestinal bleeding showed a gene-dose effect and was increased in patients receiving drugs metabolized mainly by CYP2C9 when compared to the wt allele, suggesting that genotyping CYP2C9 might identify subgroups of individuals potentially at risk of acute gastrointestinal bleeding. ${ }^{14,15,32,33}$ In the current study, only the patients' reports were used as a parameter of gastrointestinal discomfort; no endoscopic examination was performed to investigate the asymptomatic gastrointestinal side effects, and thus, small lesions may have occurred that did not affect the daily routine of the patients.

Otherwise, within the postoperative parameters examined, the volunteers' alleles for $C Y P 2 C 8^{*} 3$ or $C Y P 2 C 9$ were not correlated with any variation in the anti-inflammatory effects of piroxicam, indicating that piroxicam is capable of controlling inflammation regardless of their genotype. Other uninvestigated factors can interfere with inflammation such as postoperative dental hygiene around the extraction site.

Volunteers who underwent lower third molar surgeries, regardless of their $C Y P$ genotype, achieved satisfactory relief from postoperative pain and inflammation, with minimal risk of adverse side effects. Therefore, even for slow metabolizers of piroxicam, a daily $20 \mathrm{mg}$ oral dose of piroxicam can be effective while minimizing adverse side effects after invasive oral surgery.

The impact of genetic variants on drug responses to control inflammatory signs and adverse effects of NSAIDs is clear since giving the "right drug" to the patient is a major goal in the era of medicine excellence. Further investigations with other NSAIDs used in the postoperative period of lower third molar surgeries are necessary because this group of drugs presents considerable variations regarding the genetic influence of CYP.

\section{Conclusion}

In general, slow metabolizers of piroxicam, namely, volunteers with mutant alleles, were indifferent from normal metabolizers with the wild-type alleles and therefore did not require specialized piroxicam doses to manage postoperative pain and inflammation after surgical removal of the lower third molar.

\section{Acknowledgment}

This study was supported by the following grants: São Paulo Research Foundation (FAPESP) grant numbers 2009/17851-8 and 2014/17803-1; and National Council for Scientific and Technological Development $(\mathrm{CNPq})$ grant number 150845/2014-6. 


\section{Disclosure}

The authors report no conflicts of interest in this work.

\section{References}

1. Rollason V, Samer CF, Daali Y, Desmeules JA. Prediction by pharmacogenetics of safety and efficacy of non-steroidal anti-inflammatory drugs: a review. Curr Drug Metab. 2014;15(3):326-343.

2. Martinez C, Garcia-Martin E, Blanco G, Gamito FJ, Ladero JM, Agundez JA. The effect of the cytochrome P450 CYP2C8 polymorphism on the disposition of (R)-ibuprofen enantiomer in healthy subjects. $\mathrm{Br} J$ Clin Pharmacol. 2005;59(1):62-69.

3. Garcia-Martin E, Martinez C, Ladero JM, Agundez JA. Interethnic and intraethnic variability of CYP2C 8 and CYP2C9 polymorphisms in healthy individuals. Mol Diagn Ther. 2006;10(1):29-40.

4. Agundez JA, Garcia-Martin E, Martinez C. Genetically based impairment in CYP2C8- and CYP2C9-dependent NSAID metabolism as a risk factor for gastrointestinal bleeding: is a combination of pharmacogenomics and metabolomics required to improve personalized medicine? Expert Opin Drug Metab Toxicol. 2009;5(6):607-620.

5. Martinez C, Blanco G, Ladero JM, et al. Genetic predisposition to acute gastrointestinal bleeding after NSAIDs use. Br J Pharmacol. 2004;141(2):205-208.

6. Sanderson S, Emery J, Higgins J. CYP2C9 gene variants, drug dose, and bleeding risk in warfarin-treated patients: a HuGEnet systematic review and meta-analysis. Genet Med. 2005;7(2):97-104.

7. Meyer UA. Pharmacogenetics - five decades of therapeutic lessons from genetic diversity. Nat Rev Genet. 2004;5(9):669-676.

8. Pennisi E. A closer look at SNPs suggests difficulties. Science. 1998;281(5384):1787-1789.

9. Lopez-Rodriguez R, Novalbos J, Gallego-Sandin S, et al. Influence of CYP2C8 and CYP2C9 polymorphisms on pharmacokinetic and pharmacodynamic parameters of racemic and enantiomeric forms of ibuprofen in healthy volunteers. Pharmacol Res. 2008;58(1): $77-84$.

10. Au N, Rettie AE. Pharmacogenomics of 4-hydroxycoumarin anticoagulants. Drug Metab Rev. 2008;40(2):355-375.

11. Peiro AM, Novalbos J, Zapater P, et al. Pharmacogenetic relevance of the CYP2C9*3 allele in a tenoxicam bioequivalence study performed on Spaniards. Pharmacol Res. 2009;59(1):62-68.

12. Vianna-Jorge R, Perini JA, Rondinelli E, Suarez-Kurtz G. CYP2C9 genotypes and the pharmacokinetics of tenoxicam in Brazilians. Clin Pharmacol Ther. 2004;76(1):18-26.

13. Perini JA, Vianna-Jorge R, Brogliato AR, Suarez-Kurtz G. Influence of CYP2C9 genotypes on the pharmacokinetics and pharmacodynamics of piroxicam. Clin Pharmacol Ther. 2005;78(4):362-369.

14. Rodrigues AD. Impact of CYP2C9 genotype on pharmacokinetics: are all cyclooxygenase inhibitors the same? Drug Metab Dispos. 2005;33(11):1567-1575.

15. Samer CF, Lorenzini KI, Rollason V, Daali Y, Desmeules JA. Applications of CYP450 testing in the clinical setting. Mol Diagn Ther. 2013;17(3):165-184.

16. Zupelari-Goncalves P, Weckwerth GM, Calvo AM, et al. Efficacy of oral diclofenac with or without codeine for pain control after invasive bilateral third molar extractions. Int J Oral Maxillofac Surg. 2017;46(5):621-627.

17. Calvo AM, Brozoski DT, Giglio FP, et al. Are antibiotics necessary after lower third molar removal? Oral Surg Oral Med Oral Pathol Oral Radiol. 2012;114(5 suppl):S199-S208.
18. Colombini BL, Modena KC, Calvo AM, et al. Articaine and mepivacaine efficacy in postoperative analgesia for lower third molar removal: a double-blind, randomized, crossover study. Oral Surg Oral Med Oral Pathol Oral Radiol Endod. 2006;102(2):169-174.

19. Benetello V, Sakamoto FC, Giglio FP, et al. The selective and nonselective cyclooxygenase inhibitors valdecoxib and piroxicam induce the same postoperative analgesia and control of trismus and swelling after lower third molar removal. Braz J Med Biol Res. 2007;40(8):1133-1140.

20. Calvo AM, Sakai VT, Giglio FP, et al. Analgesic and anti-inflammatory dose-response relationship of 7.5 and $15 \mathrm{mg}$ meloxicam after lower third molar removal: a double-blind, randomized, crossover study. Int $J$ Oral Maxillofac Surg. 2007;36(1):26-31.

21. Santos CF, Modena KC, Giglio FP, et al. Epinephrine concentration $(1: 100,000$ or $1: 200,000)$ does not affect the clinical efficacy of $4 \%$ articaine for lower third molar removal: a double-blind, randomized, crossover study. J Oral Maxillofac Surg. 2007;65(12): $2445-2452$.

22. Gregorio LV, Giglio FP, Sakai VT, et al. A comparison of the clinical anesthetic efficacy of $4 \%$ articaine and $0.5 \%$ bupivacaine (both with 1:200,000 epinephrine) for lower third molar removal. Oral Surg Oral Med Oral Pathol Oral Radiol Endod. 2008;106(1):19-28.

23. Senes AM, Calvo AM, Colombini-Ishikiriama BL, et al. Efficacy and safety of $2 \%$ and $4 \%$ articaine for lower third molar surgery. $J$ Dent Res. 2015;94(9 suppl):166S-173S.

24. Weckwerth GM, Simoneti LF, Zupelari-Goncalves P, et al. Efficacy of naproxen with or without esomeprazole for pain and inflammation in patients after bilateral third molar extractions: a double blinded crossover study. Med Oral Patol Oral Cir Bucal. 2017;22(1):e122-e131.

25. Trindade PA, Giglio FP, Colombini-Ishikiriama BL, et al. Comparison of oral versus sublingual piroxicam during postoperative pain management after lower third molar extraction. Int J Oral Maxillofac Surg. 2011;40(3):292-297.

26. Trindade PA, Giglio FP, Colombini-Ishikiriama BL, et al. Sublingual ketorolac and sublingual piroxicam are equally effective for postoperative pain, trismus, and swelling management in lower third molar removal. Oral Surg Oral Med Oral Pathol Oral Radiol. 2012;114(1):27-34.

27. Ustun Y, Erdogan O, Esen E, Karsli ED. Comparison of the effects of 2 doses of methylprednisolone on pain, swelling, and trismus after third molar surgery. Oral Surg Oral Med Oral Pathol Oral Radiol Endod. 2003;96(5):535-539.

28. Krasniqi V, Dimovski A, Domjanovic IK, Bilic I, Bozina N. How polymorphisms of the cytochrome P450 genes affect ibuprofen and diclofenac metabolism and toxicity. Arh Hig Rada Toksikol. 2016;67(1):1-8.

29. Senagore AJ, Champagne BJ, Dosokey E, et al. Pharmacogeneticsguided analgesics in major abdominal surgery: further benefits within an enhanced recovery protocol. Am J Surg. 2017;213(3):467-472.

30. Murto K, Lamontagne C, McFaul C, et al. Celecoxib pharmacogenetics and pediatric adenotonsillectomy: a double-blinded randomized controlled study. Can J Anaesth. 2015;62(7):785-797.

31. Jensen MP, Martin SA, Cheung R. The meaning of pain relief in a clinical trial. J Pain. 2005;6(6):400-406.

32. Carbonell N, Verstuyft C, Massard J, et al. CYP2C $9 * 3$ loss-of-function allele is associated with acute upper gastrointestinal bleeding related to the use of NSAIDs other than aspirin. Clin Pharmacol Ther. 2010;87(6):693-698.

33. Blanco G, Martinez C, Ladero JM, et al. Interaction of CYP2C8 and CYP2C9 genotypes modifies the risk for nonsteroidal anti-inflammatory drugs-related acute gastrointestinal bleeding. Pharmacogenet Genomics. 2008;18(1):37-43. 
The Journal of Pain Research is an international, peer reviewed, open access, online journal that welcomes laboratory and clinical findings in the fields of pain research and the prevention and management of pain. Original research, reviews, symposium reports, hypothesis formation and commentaries are all considered for publication
The manuscript management system is completely online and includes a very quick and fair peer-review system, which is all easy to use. Visit http://www.dovepress.com/testimonials.php to read real quotes from published authors. 